Musées, Patrimoine et Culture scientifiques et techniques

$190 \mid 2020$

juillet-août 2020

\title{
La crise 2020, un défi particulier pour les structures de culture scientifique
}

Andréa Parés et Rebecca Bilon

\section{OpenEdition}

\section{Journals}

Édition électronique

URL : https://journals.openedition.org/ocim/3888

DOI : 10.4000/ocim.3888

ISSN : 2108-646X

Éditeur

OCIM

Édition imprimée

Date de publication : 1 juillet 2020

Pagination : 8-11

ISSN : 0994-1908

Référence électronique

Andréa Parés et Rebecca Bilon, « La crise 2020, un défi particulier pour les structures de culture scientifique », La Lettre de I'OCIM [En ligne], 190 | 2020, mis en ligne le 01 juillet 2021, consulté le 17 juillet 2021. URL : http://journals.openedition.org/ocim/3888 ; DOI : https://doi.org/10.4000/ocim 3888

Ce document a été généré automatiquement le 17 juillet 2021.

Tous droits réservés 


\title{
La crise 2020, un défi particulier pour les structures de culture scientifique
}

\author{
Andréa Parés et Rebecca Bilon
}

Comment donner à voir les phases d'analyse et de recherche et illus-trer les questions scientifiques qui occupent notre actualité ? Boîtes de Petri exposées au Micropia Museum à Amsterdam, musée dédié aux micro-organismes.

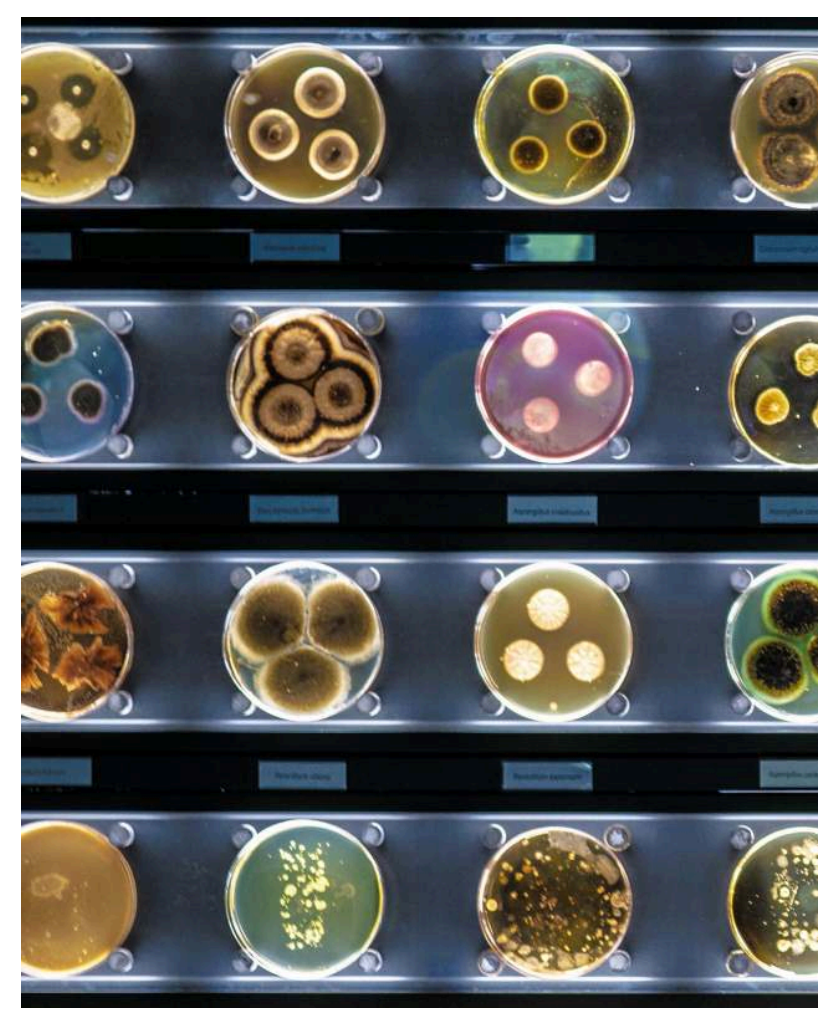

(C) Y. Caradec (Flickr CC BY-SA 2.0) 
$1 \mathrm{Au}$ moment où la société n'a jamais autant porté d'intérêt aux sciences et tente de comprendre les défis de notre temps, les structures de culture scientifique, technique et industrielle (CSTI) peuvent se distinguer dans la réflexion collective menée dans le secteur culturel.

2 La crise sanitaire actuelle illustre parfaitement une tendance de fond : la remise en cause croissante du discours scientifique « institutionnel » parallèlement à l'émergence de vérités alternatives aux sources discutables. Plus que jamais - alors que l'opinion semble primer sur l'expertise - il nous semble essentiel de permettre au citoyen d'accéder à une information scientifique exacte, mais aussi de s'approprier les outils indispensables à une certaine autonomie intellectuelle.

3 S'il est un point qui aura été unanimement critiqué pendant cette crise, c'est bien le manque de distance avec l'actualité, exacerbé par la multiplicité des intervenants. Sur tous les canaux de communication, des politiques ou des anonymes s'improvisent médecins ; tandis que certains médecins rassemblent des internautes comme le feraient des partis politiques. L'omniprésence de la parole scientifique - contradictoire ou parfois militante - n'a fait que la diluer et a malmené la crédibilité que les scientifiques et nos institutions mettent tant de temps à construire.

4 Comment alors accompagner le citoyen dans cette abondance de données, de sources et d'informations où se mêlent faits avérés, hypothèses et opinions?

5 Face à ce changement de paradigme si vif sur notre rapport aux sciences, aux autres, quels rôles jouent les muséums d'Histoire naturelle et plus largement les structures de CSTI ?

6 Dans le débat public sur la pandémie, les fake news ont constitué l'ennemi identifié du gouvernement. Presse et institutions de cultures scientifiques se sont également mobilisées en faveur du fact-checking.

7 Comme pour les autres structures du secteur culturel, celles de CSTI ont bénéficié d'une vague d'entraide à plusieurs niveaux. Elle s'est notamment matérialisée par des bases de données compilant les publications scientifiques réunies par la communauté des acteurs de la culture scientifique ${ }^{1}$, mais également par des données retravaillées par ces mêmes acteurs mêlant souvent plusieurs sources et propos directement rapportés de chercheurs concernés par l'épidémie. 
"Les collections permettent d'appuyer le discours scientifique par l'objet ». Intestin présenté lors de l'exposition Microbiote (Cité des sciences et de l'industrie, 2019).

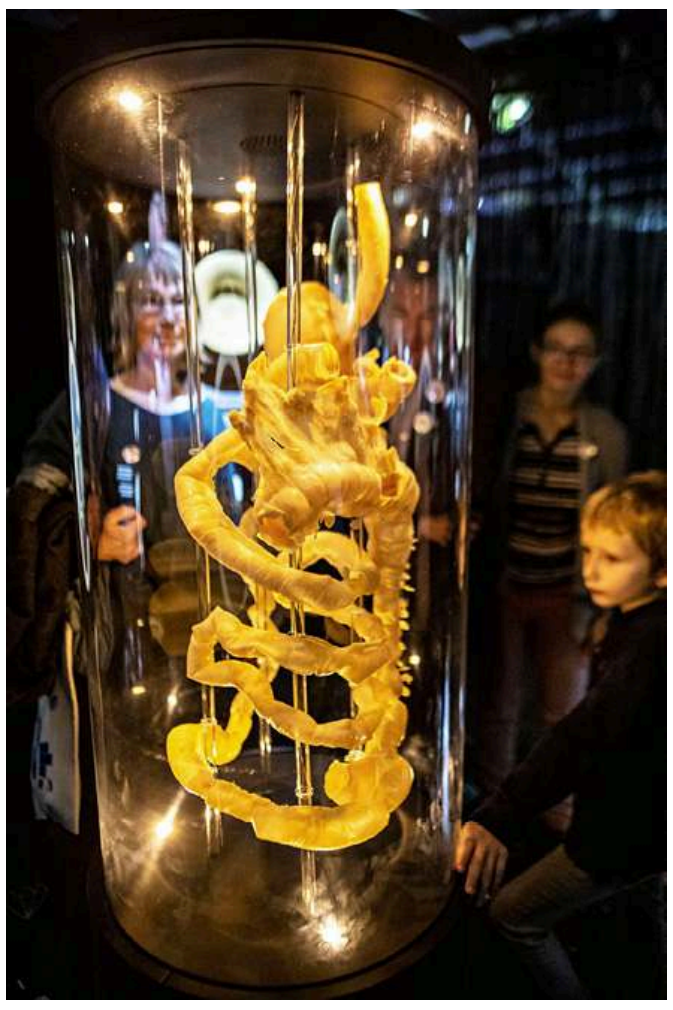

(C) Ph. Levy/EPPDCSI 
Grâce au programme Patstec, des milliers d'objets et d'instruments de recherche ont pu être sauvegardés (Fluxmètre Grassot, collections de Sciences et Techniques, université de Bourgogne).

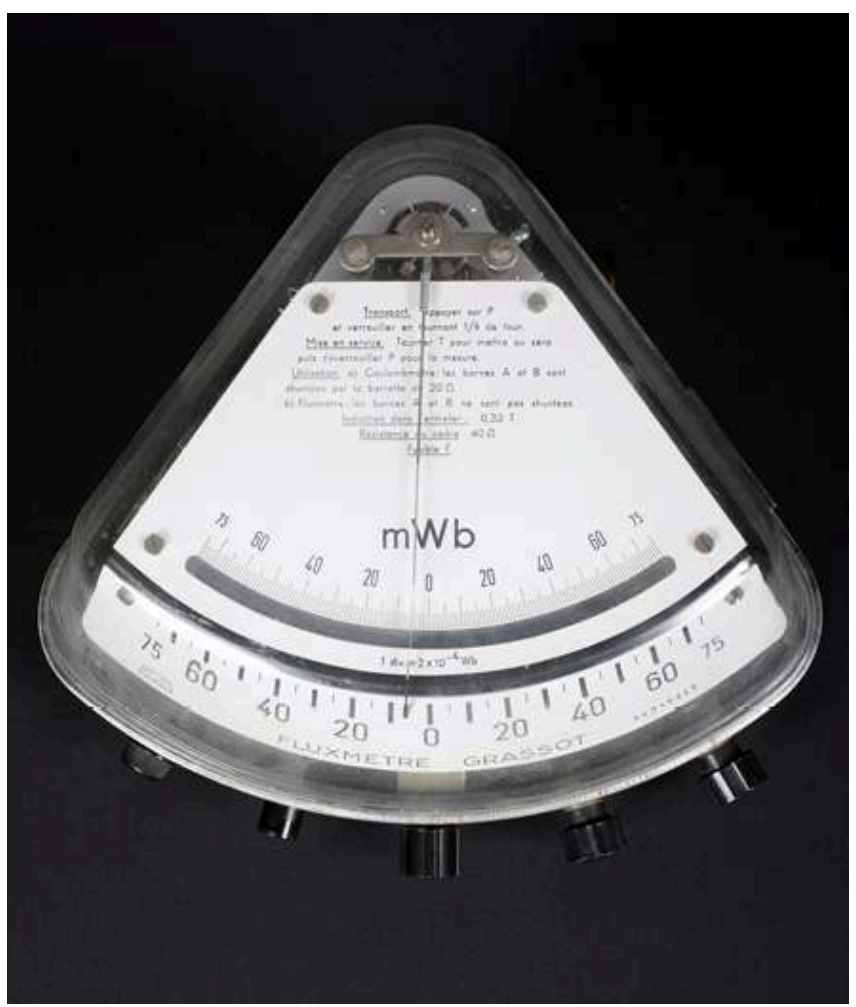

(c) V. Arbelet/université de Bourgogne

8 Forts de leurs réseaux et par ces outils partagés, les structures de CSTI défendent d'une même voix la crédibilité et le raisonnement scientifiques avant tout, gages de confiance vis-à-vis de leurs publics. Présents sur l'ensemble du territoire, proches du citoyen, ils ont un rôle de modérateur et de médiateur à jouer de plus en plus capital. Ils forment des liens entre leurs interlocuteurs privilégiés, publics, universitaires, chercheurs et experts.

9 À chaque temps de l'histoire, la société a porté un regard sur les sciences, comme en témoigne la création d'institutions de culture scientifique : cabinets de curiosité, chambres des merveilles, muséums, écomusées, Palais de la découverte, Cité des sciences, fablabs, labo-musées... Entre leurs murs se sont joués des engagements forts, jamais inébranlables, autour de la pensée scientifique dans nos sociétés occidentales. Par ses objets d'étude et le propos scientifique, dans une logique interdisciplinaire, le discours des structures de CSTI considère la contradiction, intègre la discussion, et le « croisement » des regards entre amateurs, experts, chercheurs.

10 Réagir à l'actualité est cependant un exercice délicat, lorsque la ferveur des discussions rend la neutralité impossible et la critique irrecevable. Elle rappelle que la science se construit par tâtonnements, expérimentations, via une communauté d'experts en permanente concertation, à l'opposé de l'image dogmatique que la société (et les publicitaires) a longtemps alimenté.

11 Par la compréhension de ces faits, la pratique de l'épistémologie et la culture de l'analyse critique, les structures de CSTI se positionnent comme des interlocuteurs stratégiques de cette crise. Autant de pratiques professionnelles permettant aujourd'hui ou demain de l'objectiver et peut-être de mieux l'absorber. 

exemple de l'exposition Microbiotes à la Cité des sciences et de l'industrie. Aux PaysBas, le musée Micropia, entièrement dédié aux micro-organismes, expose boîtes de Petri et scanner à microbes.

18 En 2003, le Cnam a ouvert la marche sur le défi de la sauvegarde du patrimoine scientifique contemporain. Via le premier programme Patstec, des milliers d'objets et d'instruments d'unité de recherche ont été sauvegardés. Presque 20 ans plus tard, l'enjeu est toujours aussi important et rejoint celui plus large de renseigner les métiers de sciences, les savoir-faire et la culture matérielle scientifique moderne.

Universitaires, chercheurs en sont les protagonistes et forment des alliés essentiels pour la revalorisation de ce domaine. Cet événement nous rappelle plus que jamais la pertinence du rôle des structures de CSTI comme médiateurs entre recherche et public, défenseurs de la culture scientifique sur le territoire. 
"En illustrant la science en train se faire, on constitue dans le même temps une archive précieuse de nos sociétés et des enjeux de la recherche » (Penicillium maximae, Micropia Museum).

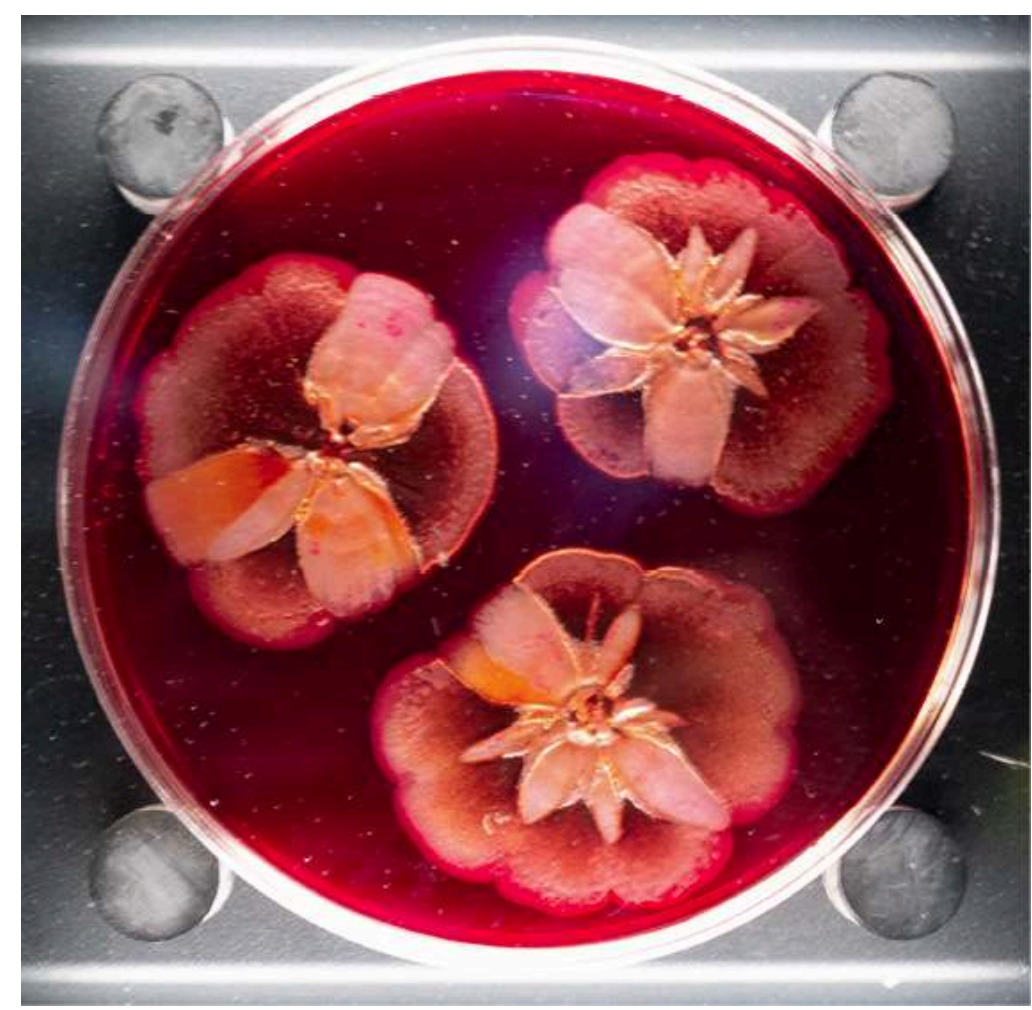

(c) Y. Caradec (Flickr CC BY-SA 2.0)

Les centres de culture scientifique font face aux mêmes interrogations et craintes que leurs confrères du secteur culturel. Leur histoire et parcours sont multiples et font voir des qualités complémentaires d'animateur des réseaux scientifiques territoriaux, d'expert en médiation et de défenseur de la culture scientifique. Loin de se limiter aux parcours d'exposition, ces structures se distinguent par la multiplicité des formats de médiations et d'interventions sur le territoire (via des associations ou des universités, des dispositifs innovants hors les murs) notamment auprès des publics les plus éloignés. Ces ressources affirmées constituent leur force de résilience face à cette crise et, dans le même temps, une légitimité fonctionnelle pour répondre aux questionnements soulevés par cette actualité.

21 Il convient aujourd'hui de les faire connaître et reconnaître de nos confrères du secteur culturel sur des échelles locale et nationale. Gageons que cette période de collaborations effectives s'inscrive dans la durée et que les enjeux relatifs au patrimoine scientifique puissent 


\section{NOTES}

1. Distances - Regards sur une situation inédite, l'épidémie de Covid-19, la lettre de l'Ocim, n²189, mai-juin 2020, 110 p.

\section{RÉSUMÉS}

L'épidémie de Covid-19 a mis en lumière ce qui était déjà une évidence : la médiation de l'information scientifique est un enjeu de société et de santé publique. Interlocuteurs privilégiés et expérimentés, les structures de culture scientifique doivent plus que jamais jouer leur rôle de transmission et accompagner les populations.

\section{AUTEURS}

\section{ANDRÉA PARÉS}

Conservatrice au muséum départemental du Var apares@var.fr

REBECCA BILON

Directrice du muséum de Grenoble

rebecca.bilon@grenoble.fr 